\title{
REVIEW
}

\section{Pressure ulcers in people with spinal cord injury in developing nations}

\author{
EC Zakrasek ${ }^{1}$, G Creasey ${ }^{2,3}$ and JD Crew ${ }^{4}$
}

Study design: Literature review.

Objectives: To explore the prevalence or incidence, risk factors, and costs of pressure ulcers among individuals with spinal cord injury (SCI), specifically in the context of the developing world. To highlight important targets for intervention and research for pressure ulcer management the world over.

Setting: World Bank 'low-income' and 'middle-income' countries with a gross national income per capita $<\$ 12746$.

Methods: PubMed search.

Results: $\quad \mathrm{SCl}$-associated pressure ulcers are very prevalent in developing nations; however, reported prevalence and incidence numbers are highly variable. Risk factors for pressure ulcers are similar in developed and developing countries however many of the risk factors are more prevalent in developing nations.

Conclusion: $\mathrm{SCl}$-associated pressure ulcers are common but can be prevented in the developing world. Key targets for interventions include acute care, nurse-to-patient ratios, support surfaces and education.

Spinal Cord (2015) 53, 7-13; doi:10.1038/sc.2014.179; published online 4 November 2014

\section{INTRODUCTION}

Despite many advances in spine surgery and rehabilitation medicine, there remain significant morbidity and mortality associated with spinal cord injury (SCI). Even the seemingly simple problem of pressure ulcers (PUs) remains a common SCI complication. In developing nations, defined here as World Bank 'low-income' and 'middleincome' countries with a gross national income per capita $<\$ 12746,{ }^{1}$ SCI care providers face unique challenges inherent in resource scarcity. Following injury, individuals in developing countries may travel for days over rough terrain just to reach a medical facility able to address their needs. These facilities often lack such basic equipment as pressure relief mattresses and patient-to-nurse ratios are typically high. Even if fortunate enough to meet a spine surgeon, few spinal cord injured patients in these countries will encounter a trained rehabilitation specialist. ${ }^{2}$ Finally, reintegration into the community after discharge is awash in obstacles such as environmental inaccessibility, limited adaptive equipment, financial hardship and, frequently, social isolation. ${ }^{3}$ One might expect the combination of any number of these scenarios to increase the rate of SCI complications such as PUs in developing nations. Indeed, Burns and O'Connell ${ }^{4}$ noted that PUs affect 'practically 100\%' of people with SCI in the developing world.

PUs are not specific to SCI but are frequent complications of hospitalized and immobilized patients in numerous clinical scenarios. ${ }^{5}$ Nevertheless, the sensory loss, motor impairment and skin changes of SCI make individuals with SCI uniquely vulnerable to PU development. Importantly, there are also external and modifiable risk factors for PU formation. Many of these modifiable risk factors are more prominent in developing nations.

The challenges of SCI care in developing countries have been described previously. ${ }^{6}$ That said, in light of recent publicity surrounding natural disasters such as the earthquakes in Pakistan (2005), China (2008) and Haiti (2010), there has been a resurgence of interest in improved rehabilitation medicine in the developing world. $3,4,7,8$ Physicians and researchers in these parts of the world are starting to document local SCI care and complications, including information about the prevalence and management of PUs. To the authors' knowledge, there are currently no literature reviews compiling these data and examining the prevalence of PUs in the developing world. This article is a compilation and analysis of these papers about SCI-related PUs in the developing world that examines the prevalence and explores the risks, costs and possible solutions to this common problem.

\section{MATERIALS AND METHODS}

A PubMed search of journal articles written in English between 1998 and August 2014 was carried out using the following search terms: 'spinal cord injury', 'pressure ulcers'. This resulted in 938 references. The abstracts of relevant titles were reviewed and, when relevant and available, the full text was then reviewed. This search yielded 17 articles containing pressure ulcer prevalence or incidence data in developing nations. A citation review of these 17 articles and of Burns and O'Connell ${ }^{4}$ captured six more articles that had been missed in our initial search. The majority of articles were of low level of evidence, such as case series or expert opinion papers. There were no controlled trials, case-control studies or systematic reviews.

\footnotetext{
${ }^{1}$ Department of Physical Medicine and Rehabilitation, Stanford University, Palo Alto, CA, USA; ${ }^{2}$ Spinal Cord Injury Service, VA Palo Alto Health Care System, Palo Alto, CA, USA; ${ }^{3}$ Department of Neurosurgery, Stanford University, Palo Alto, CA, USA and ${ }^{4}$ Spinal Cord Injury Service, Santa Clara Valley Medical Center, San Jose, CA, USA Correspondence: Dr EC Zakrasek, Department of Physical Medicine and Rehabilitation, Stanford University, 450 Broadway Street, Pavilion C, MC 6342, Redwood City, CA 94063 USA.

E-mail: ezak@stanford.edu

Received 17 May 2014; revised 22 September 2014; accepted 28 September 2014; published online 4 November 2014
} 


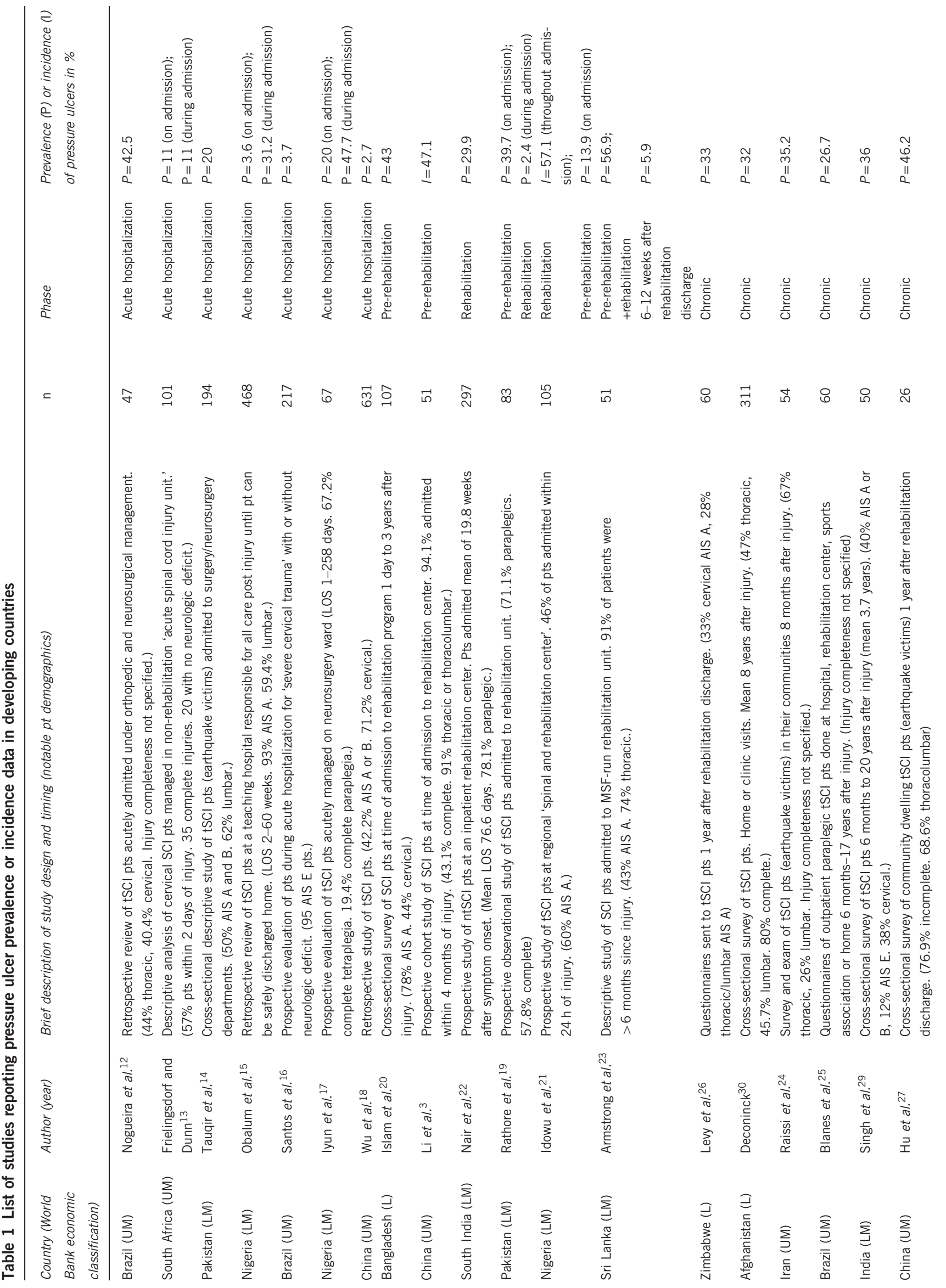




\section{RESULTS}

It is currently impossible to accurately report the true prevalence of SCI-related PUs in the developing world. In many parts of the world, the prevalence of SCI itself is unknown. First, the concept of the 'developing world' encompasses a heterogeneous group of countries with variable resources and cultural attitudes towards health and disability. Second, practitioners of rehabilitation medicine, and therefore data on rehabilitation medicine, are very scarce in many of the world's poorest nations, areas where one might imagine medical complications of SCI to be the greatest. Finally, people with SCI are often relegated to remote and rural homes far from mainstream society, making data collection quite difficult. ${ }^{9-11}$

As demonstrated in Table 1, prevalence and incidence data about SCI-related PUs is highly variable, which may or may not reflect reality. Eleven articles reported PU prevalence during initial inpatient hospitalization and/or prior to rehabilitation admission ${ }^{3,12-21}$ and four articles report PU prevalence or incidence during SCI rehabilitation programs. ${ }^{19,21-23}$ The demarcation of this time period, however, was as variable as 1 day to 3 years post injury, making comparison and discussion of these prevalence statistics challenging. Ten articles were identified that reported the prevalence or incidence of PUs in community dwellers from 6 months to 20 years after injury. ${ }^{24-33}$ Of note, very few of these study subjects were reported to have undergone SCI rehabilitation. These 10 papers reported a PU prevalence of $26.7-46.2 \%$, mean of $35.2 \%$. The only paper to cite a PU prevalence $<30 \%(26.7 \%)$ was drawn from a population only of persons with paraplegia in Brazil. ${ }^{25}$

Although this is an alarmingly high PU prevalence, this probably under-represents the true prevalence of PUs in the developing world. Many of the world's poorest nations with the highest SCI-associated mortality are not represented in these statistics. ${ }^{34}$ In addition, the hospitals and clinics that performed the cited studies may not have the financial resources or infrastructure to document and report all PUs reliably. ${ }^{28}$ Furthermore, individuals with more severe mobility impairments and those who live remotely are unlikely to be captured by such studies because of limited transportation options in many low resource communities.

Even if only a rough estimate, the findings above do suggest that the prevalence of PUs in developing nations is greater than in the developed world. By contrast, Chen et al. ${ }^{35}$ reported a PU prevalence of $11.5 \%$ at 1 year after injury and $21 \%$ at 15 years post injury in the United States.

A description of SCI-related PUs is incomplete without addressing risk factors, costs, consequences, prevention and management strategies. The following discussion will focus on these issues specifically in the context of the developing world.

\section{DISCUSSION}

\section{Risk factors}

Even though most studies identifying risk factors for PU formation have originated in the developed world, the identified risk factors are undoubtedly also germane to SCI care in the developing world. Furthermore, many of these risk factors are more commonly encountered in developing countries.

Income. Low household income in the United States is associated with increased PU risk. ${ }^{36}$ Although this association has many confounding variables and is difficult to extrapolate to nations where average annual income is often a small percentage of that of the United States, decreased financial resources probably increase PU risk worldwide. One could speculate, for example, that financially poor 
individuals would be unable to afford quality pressure relief cushions, mobility aids, caregiver support and/or proper nutrition. In addition, low household income might have a more pronounced effect on SCI complication rates in regions where healthcare expenses are predominantly paid out-of-pocket and significant medical events have catastrophic effects on family finances. ${ }^{37}$ Finally, there are typically fewer social welfare programs provided by the governments of these regions to assist the poor in accessing healthcare. ${ }^{38}$

Education. Fewer years of education has been identified as a risk factor for PU development in several studies from developed nations. ${ }^{39,40}$ In developing nations with comparatively low average educational level, this is also a significant barrier to care and a risk factor for SCI complications. ${ }^{8,9,31,41}$ Educational deficiencies in these nations are twofold. First, people who suffer a SCI often have fewer years of education and poor health literacy. Second, and perhaps more importantly, few care providers in the developing world have had formal SCI education. ${ }^{2,42}$ Because these healthcare providers lack SCI training, they struggle to manage PU risk factors in their patients and often fail to educate their patients about ongoing PU prevention strategies. In their letter to the editor responding to the 2012 study of PU risks in Iran by Eslami et al., ${ }^{31}$ Rathore and Mansoor ${ }^{43}$ note that 'lack of knowledge regarding PU prevention on the part of the doctors' is one of the 'four major reasons for PU occurrence' in Pakistan. Indeed, without access to specialty guidance, even the most educated and motivated person with SCI is prone to complications.

Immobility. Patient immobility is a known risk factor for PUs. When investigating activity level among people with SCI in developing countries, it is important to also consider nonphysical barriers. In countries such as Pakistan and Nepal, the mobility of individuals with SCI is 'restricted' by environmental and social barriers: 'A quadriplegic in a developing country leads a very restricted life in most of the cases. Majority of them are confined to their homes and spend most of the time in their beds or wheelchairs, with no regular pressure relief. ${ }^{43}$ 'Based on self-report, participants spent an average of $5 \mathrm{~h}$ per day in their wheelchair. The remaining time was spent primarily in bed. Two had no mattresses on wooden bed frames; the rest had mattresses made of locally available foam or cotton materials. ${ }^{28}$ As these authors illustrate, mobility may be limited by more than neurologic deficits. Shore and Juillerat ${ }^{44}$ have shown that by increasing mobility through donated wheelchairs, neurologically impaired patients in Vietnam, Chile and India had a significant decrease in PUs. Their proposed explanation is that wheelchair propulsion maneuvers induce pressure relief. Their study also demonstrated that increased community mobility was associated with increased access to care, decreased pain, increased positive mood and improved daily feelings about life. ${ }^{44}$ One could posit that these additional benefits may also directly or indirectly affect PU development. Taken together, in regions of the world where SCI is hidden from society and/or where inaccessibility and adaptive equipment limitations make activity difficult, individuals with SCI enjoy less mobility and therefore incur greater PU risk.

Other. Although far less numerous than articles from well-resourced countries, several studies identifying risk factors for PU formation have emerged directly from developing countries. In Nigeria and Turkey for example, malnutrition has been shown to be a risk factor for PU formation, ${ }^{21,45}$ a finding with mixed evidence in the developing world. ${ }^{40}$ This is of notable significance given the increased prevalence of malnutrition in developing countries and the fact that malnutrition is known to impair wound healing. ${ }^{46,47}$
In 1988, Mawson et al. ${ }^{48}$ demonstrated the influence of acute SCI management on PU development in the United States. Despite improved acute SCI management in the developed world, this remains a major issue in developing countries with many illustrative examples. In Nigeria, Ahidjo et al. ${ }^{49}$ found that only $5.4 \%$ of spinal cord injured patients were transported to the hospital by ambulance, and $67.9 \%$ presented $>24 \mathrm{~h}$ after injury. Meanwhile, Idowu et al. ${ }^{21}$ found that delayed hospital presentation after injury in Nigeria was associated with more PUs at the time of admission. In South Africa, Fielingsdorf and Dunn ${ }^{13}$ reported an $11 \%$ incidence of PUs on initial presentation that was attributed to delayed admission due to 'patients being transported over extensive distances' on 'hard fracture boards'. In Zimbabwe, Levy et al. ${ }^{26}$ reported that patients 'rarely' reach proper care in $<24 \mathrm{~h}$ and they are 'invariably picked up by unskilled people' with 'inadequate transport'. Rathore et al. ${ }^{19}$ depicts the epitome of unskilled pre-hospital transport in the description of an SCI patient in Pakistan who 'was brought to the hospital on a bullock cart'. Even in parts of Brazil, only $21 \%$ of SCI patients were admitted to the hospital within $4 \mathrm{~h}$ of trauma with $11.6 \%$ hospitalized $>48 \mathrm{~h}$ after injury secondary to long transport time. ${ }^{50}$ In contrast, in New South Wales, the average time until admission after traumatic SCI is $12 \mathrm{~h}^{51}$ Importantly, early PUs are preventable with the implementation of pre-hospital transport protocols. ${ }^{52}$

\section{Costs and consequences}

PUs beget significant morbidity and mortality among individuals with SCI the world over. By breaching the protective skin barrier, PUs lead to local, systemic, chronic or even life-threatening infections. ${ }^{53}$ PUs and their associated infections are associated with increased re-hospitalization rates, ${ }^{28,54}$ increased duration of hospitalization, ${ }^{21}$ decreased life expectancy and death. ${ }^{26,34,54-57}$

The costs of PUs extend well beyond the expense of infectious complications. PUs impair quality of life due to pain, disfigurement, fear and anxiety. ${ }^{58}$ Individuals with PUs are less likely to be employed, engage in fewer social outings and have decreased leisure time activities. ${ }^{56,59}$ Early PUs prolong acute hospitalization, delay initiation of rehabilitation and, in some cases, completely preclude admission into rehabilitation centers. ${ }^{13,54}$ In purely economic terms, PUs are very expensive. ${ }^{17,56,60}$ Cost estimates for PU care in all-comers have been reported as high as $\$ 9000$ Canadian a month for community dwellers with high grade ulcers, \$130 000 American per hospital admission for hospital-acquired ulcers in the United States and up to $4 \%$ of the National Health Service Expenditure in the UK annually. ${ }^{60-62}$ Although such estimates are difficult to extrapolate to developing world settings, it has been reported that PUs account for one-fourth of the cost of caring for SCI patients in Nigeria. ${ }^{17}$ Although imperfect, these cost estimates certainly highlight the financial toll of PUs.

\section{Prevention and management}

Over 50 years have passed since Sir Ludwig Guttmann ${ }^{63}$ wrote that, 'there is still a definite lack of guidance in the prevention and treatment of bed sores, and our teaching methods to students of both the medical and the nursing professions could be vastly improved in this respect'. This sentiment still holds true, especially in developing countries. Given the high prevalence and cost of PUs in both SCI and non-SCI populations, there are a multitude of studies on PU prevention and management. Although recent research has supported a variety of new, 'high tech' management approaches to PUs, many of these interventions are impractical or financially prohibitive in developing nations. Nonetheless, there exist low-cost, proven strategies 
that could constitute an effective foundation for PU prevention and management in the developing world.

Repositioning. The best management strategy for PUs is prevention, and patient repositioning has been the foundation for PU prevention since the days of Guttmann. ${ }^{58,63}$ Though a simple intervention, patient repositioning can be quite resource intensive, particularly for those who require significant physical assistance for turning. Patient repositioning highlights an important issue in developing nations: nurse-to-patient ratio. In a Nigerian teaching hospital, for example, a single nurse is responsible for seven SCI patients. ${ }^{17}$ If a patient is to be turned every $2 \mathrm{~h}$, with seven patients assigned to one nurse and several minutes dedicated to each turning maneuver, effective repositioning alone could consume a third or more of a nurse's time. Moreover, patient turning often requires more than one attendee. Numerous authors have thus highlighted the necessity of increasing the ratio of nurses-to-patients ${ }^{15,17,64}$ or even the establishment of dedicated 'turning teams'. ${ }^{26}$

In places such as Nigeria and Turkey with low nurse-to-patient ratios, the burden of many basic patient care activities, such as repositioning, often falls on family members and friends. ${ }^{65,66}$ Nursing staff are encumbered by the more 'essential' tasks of administering medications and monitoring vital signs and thus have limited time for 'caring activities' such as patient turning. ${ }^{65}$ In Nigeria and Uganda, training family members in patient care is not only effective but also essential to successful patient outcomes. ${ }^{66,67}$ In fact, for Nwankwo's (2003) 12-week rehabilitation program in Nigeria, having an adult care aid present was a prerequisite for program participation. Unfortunately, dedicated caregivers are not always available. As underscored by Gosselin and Coppotelli ${ }^{34}$ in Sierra Leone, 'caregivers already stretching their survival skills on a daily basis, have little time or resources to prevent or treat complications such as pressure sores'.

Family participation is heavily influenced by cultural beliefs and socioeconomics. Moreover, the use of family members as care providers can have both positive and adverse effects in SCI. On one hand, family involvement has been shown to 'foster co-operation' and 'non-abandonment' of disabled relations. ${ }^{66}$ On the other hand, too much family involvement can actually impair the development of independence of the individual with SCI. ${ }^{42}$

Pressure relief surfaces. In addition to pressure relief maneuvers, pressure relief surfaces also has a large role in preventing pressure ulceration. In her follow-up study of individuals with SCI in Nepal, Scovil et al.' ${ }^{28}$ participants were given cushion-less wheelchairs and 'all but one were using wheelchair cushions made of poor-quality locally available foam with vinyl covers'. Most study participants spent the majority of their time in bed where pressure relief surfaces were also suboptimal: 'Two had no mattresses on wooden bed frames; the rest had mattresses made of locally available foam or cotton materials'. ${ }^{28}$ Although these conditions are less than ideal when compared with cushions and mattresses in the developed world, even simple pressure relief surfaces are more effective than nothing at all. Several recent studies have shown that very low-cost pressure relief surfaces can have a large impact in reducing $\mathrm{PU}$ incidence and severity. Nwadinigwe et al. ${ }^{68}$ showed that water mattresses decreased the incidence and magnitude of PUs, thus decreasing hospital length of stay in a Nigerian Hospital. In Malaysia, Ooi and Julia ${ }^{69}$ have shown that the inner tube of a Vespa scooter costing US\$4 is a useful wheelchair cushion whereas Guimaraes and Mann ${ }^{70}$ created the cheap (US\$6), durable and effective 'Tuball' cushion from bicycle inner tubes and plastic balls for use in Brazil. Medical equipment intended for developing nations must be inexpensive, practical, durable and easily repairable. ${ }^{4}$ Furthermore, such equipment must be tailored to the context of the developing nation in question and users be trained on the proper use of the device. As exemplified by Raissi et al. ${ }^{24}$ in an Iranian study, even if SCI patients are supplied with pressure relief equipment at zero cost, these supplies are futile if not used or improperly used: 'Most of the patients did not use their beds because of inappropriate height, the quality of the beds, and living habits. Few of the patients who used the Roho cushions knew how to inflate the cushion appropriately; the pressure was usually high'.

Education. Perhaps the most important ingredient for the prevention and management of PUs is education. The goal of improving education applies not only to the patient but also to the patient's physician, nurse, therapist, family and community. In order to live successfully with SCI, individuals need to understand the possible complications of their condition, a knowledge base that often begins in rehabilitation centers. Unfortunately, in many developing nations, specialized rehabilitation centers with trained rehabilitation personnel are very rare. ${ }^{2,41}$ After the 2005 Earthquake in Pakistan, Rathore et al. ${ }^{8}$ noted fewer complications such as PUs among those with SCI when specifically treated by rehabilitation specialists, a finding that has been well-established in the developed world. ${ }^{71}$ Even without dedicated rehabilitation centers, all medical personnel who interact with SCI patients should have at least a basic understanding of SCI management, ideally learned in medical and nursing school.

Improving SCI education in the developing world is no simple task however. First, in regions of the world plagued by rampant infectious disease, poverty and/or civil unrest, care of the disabled simply falls beyond the capacity of limited healthcare resources. Second, the multitude of languages and dialects, a poor understanding of human anatomy and physiology, and devastatingly low literacy rates in many developing nations makes dissemination of knowledge challenging. ${ }^{8}$ Finally, care providers, and especially international aid organizations, need to understand and operate within the context of their patients' lives. In a comparative analysis of people living with SCI in 14 countries representing all WHO world regions (Thailand, India, Vietnam, Malaysia, Denmark, Germany, Switzerland, New Zealand, Australia, Israel, USA, Canada, Brazil and South Africa), Reinhardt et $a .^{72}$ noted, 'health professionals know only little about the environment of their patient,' a situation likely to breed unrealistic expectations of how one is to care for oneself once living at home. Indeed, even if 'first-world' care is provided to a patient in the hospital, these efforts will go to waste if the necessary care cannot be continued after discharge. ${ }^{13}$ In other words, hospital and rehabilitation treatment strategies must be tailored to a patient's outpatient world.

Finally, the notion of education is also paramount as it applies to public awareness and dissolution of social stigmas. Community reintegration and peer support are pivotal components of success after SCI and are known to be associated with decreased rates of PUs and other SCI-related complications in the developed and developing world alike. ${ }^{28,40}$ Unfortunately, both environmental and psychosocial barriers impede community participation. In Iran, individuals with SCI report social isolation and feelings of being pitied. ${ }^{9}$ In Pakistan, disabled persons are often concealed in the home because disability is believed to bring guilt and shame upon a family. ${ }^{41,42}$ Such situations may foster depression and limit motivation towards self-care. Indeed, psychological comorbidities such as depression and anxiety themselves may foster PU development. ${ }^{40}$ In the end, more than ramps and wheelchair-accessible buildings are necessary to decrease 
complications associated with poor community accessibility; community integration will also require improved societal understanding of SCI.

\section{CONCLUSIONS AND FUTURE DIRECTIONS}

The preceding discussion supports the hypothesis that PUs are more difficult to prevent and treat in developing nations where the risk factors for PUs such as poverty, low education, limited activity level and malnutrition, are more prevalent. That said, this discussion also suggests that PU rates in the developing world can be decreased with improved acute care, adequate nursing, improved support surfaces and education.

In order to decrease the incidence of PUs in developing countries, we first need to understand the actual weight of the burden. There is currently little data on the true prevalence or cost of PUs in many regions of the developing world, regions where we expect the burden to be particularly high. Fortunately, organizations such as the International Spinal Cord Society have established data sets that could be used to standardize international data collection on PUs. ${ }^{73}$ Even with these data collection templates, however, harvesting information will be a challenge in hospitals and clinics with vast catchment areas connected by poor roads, lack of electronic records and few if any rehabilitation specialists.

Irrespective of the true statistics, there are clear targets for improving PU prevention and management and for SCI care more generally. Perhaps the most obvious deficiency highlighted here is that of dedicated rehabilitation centers and trained rehabilitation providers. Although there has been some progress in bringing rehabilitation strategies to the developing world, there is still a lack of rehabilitation medicine in many remote or impoverished regions. Tackling this deficit will be challenging. A first step towards the naissance of dedicated rehabilitation centers and providers is education. To this aim, a recent initiative by the International Spinal Cord Injury Society and other collaborating partners has developed a wide range of electronic learning modules for SCI available at no charge over the Internet (http://www.elearnsci.org). In addition, there are a variety of other useful online resources such as the Spinal Cord Injury Rehabilitation Evidence project (scireproject.com) and the Paralyzed Veterans of America Consortium for Spinal Cord Injury Clinical Practice Guidelines (http://www.pva.org), to name only a few.

Although affordable and durable medical devices for PU management do exist, further research in this area is needed. Importantly, these devices must fit within the context of the patient's environment, and patient and caregiver training with such devices is essential. Finally, public awareness campaigns are needed to minimize risk factors for PUs, to promote community integration, and to empower people with disabilities.

In many ways, management of SCI in developing countries is a unique opportunity to improve SCI care throughout the world. It is an opportunity to build on years of experience in developed nations whereas also breaking new ground. Who knows what might be discovered when a system of care is rebuilt in a different clime, with fresh insight.

Finally, though uncomfortable, it is necessary to ask the difficult question-is it worth it? In world regions where healthcare resources are slim and public health issues like infectious disease, malnutrition and fetal and maternal health have a much larger societal impact, should communities invest in improving SCI outcomes? The authors would like to suggest that the answer to this question is indisputably yes. For those who are willing to reach out beyond the borders of the developed world, there are many patients, families, providers and communities eager to learn, to heal and to thrive.

\section{DATA ARCHIVING}

There were no data to deposit.

\section{CONFLICT OF INTEREST}

The authors declare no conflict of interest.

1 Country and lending groups [cited 10 February 2013]. Available from: http://data worldbank.org/about/country-classifications/country-and-lending-groups.

2 Haig AJ, Im J, Adewole A, Nelson VS, Krabak B. Africa IRFCoPis The practice of physical medicine and rehabilitation in subSaharan Africa and Antarctica: a white pape or a black mark?. PMR 2009; 1: 421-426.

3 Li Y, Reinhardt JD, Gosney JE, Zhang X, Hu X, Chen S et al. Evaluation of functional outcomes of physical rehabilitation and medical complications in spinal cord injury victims of the Sichuan earthquake. J Rehabil Med 2012; 44: 534-540.

4 Burns AS, O'Connell $C$. The challenge of spinal cord injury care in the developing world. J Spinal Cord Med 2012; 35: 3-8.

5 Reddy M. Pressure ulcers. Clin Evid (Online) 2011; 2011: 1901

6 Shanmugasundaram TK. The care of $\mathrm{SCl}$ patients in the developing nations-can we stem the rot? Paraplegia 1988; 26: 10-11.

7 Rauch A, Baumberger M, Moise FG, von Elm E, Reinhardt JD. Rehabilitation needs assessment in persons with spinal cord injury following the 2010 earthquake in Haiti: a pilot study using an ICF-based tool. J Rehabil Med 2011; 43: 969-975.

8 Rathore FA, Farooq F, Muzammil S, New PW, Ahmad N, Haig AJ. Spinal cord injury management and rehabilitation: highlights and shortcomings from the 2005 earthquake in Pakistan. Arch Phys Med Rehabil 2008; 89: 579-585

9 Babamohamadi H, Negarandeh R, Dehghan-Nayeri N. Barriers to and facilitators of coping with spinal cord injury for Iranian patients: a qualitative study. Nurs Health Sci 2011; 13: 207-215.

10 Geyh S, Ballert C, Sinnott A, Charlifue S, Catz A, D'Andrea GJM et al. Quality of life after spinal cord injury: a comparison across six countries. Spinal Cord 2013; 51 322-326.

11 Dijkers MP, Yavuzer G, Ergin S, Weitzenkamp D, Whiteneck GG. A tale of two countries: environmental impacts on social participation after spinal cord injury. Spinal Cord 2002; 40: 351-362

12 Nogueira PC, Caliri MH, Haas VJ. Profile of patients with spinal cord injuries and occurrence of pressure ulcer at a university hospital. Rev Lat Am Enfermagem 2006; 14: $372-377$

13 Fielingsdorf K, Dunn RN. Cervical spine injury outcome-a review of 101 cases treated in a tertiary referral unit. S Afr Med J 2007; 97: 203-207.

14 Tauqir SF, Mirza S, Gul S, Ghaffar H, Zafar A. Complications in patients with spinal cord injuries sustained in an earthquake in Northern Pakistan. J Spinal Cord Med 2007; 30: 373-377.

15 Obalum DC, Giwa SO, Adekoya-Cole TO, Enweluzo GO. Profile of spinal injuries in Lagos, Nigeria. Spinal Cord 2009; 47: 134-137.

16 Santos EA, Santos Filho WJ, Possatti LL, Bittencourt LR, Fontoura EA, Botelho RV. Clinical complications in patients with severe cervical spinal trauma: a ten-year prospective study. Arq Neuropsiquiatr 2012; 70: 524-528.

17 Iyun AO, Malomo AO, Oluwatosin OM, Ademola SA, Shokunbi MT. Pattern of presentation of pressure ulcers in traumatic spinal cord injured patients in University College Hospital, Ibadan. Int Wound J 2012; 9: 206-213.

18 Wu Q, Ning GZ, Li YL, Feng HY, Feng SQ. Factors affecting the length of stay of patients with traumatic spinal cord injury in Tianjin, China. J Spinal Cord Med 2013; 36 237-242.

19 Rathore MF, Hanif S, Faroog F, Ahmad N, Mansoor SN. Traumatic spinal cord injuries at a tertiary care rehabilitation institute in Pakistan. J Pak Med Assoc 2008; 58: 53-57.

20 Islam MS, Hafez MA, Akter M. Characterization of spinal cord lesion in patients attending a specialized rehabilitation center in Bangladesh. Spinal Cord 2011; 49: 783-786.

21 Idowu OK, Yinusa W, Gbadegesin SA, Adebule GT. Risk factors for pressure ulceration in a resource constrained spinal injury service. Spinal Cord 2011; 49: 643-647.

22 Nair KP, Taly AB, Maheshwarappa BM, Kumar J, Murali T, Rao S. Nontraumatic spinal cord lesions: a prospective study of medical complications during in-patient rehabilitation. Spinal Cord 2005; 43: 558-564.

23 Armstrong JC, Nichols BE, Wilson JM, Cosico RA, Shanks L. Spinal cord injury in the emergency context: review of program outcomes of a spinal cord injury rehabilitation program in Sri Lanka. Confl Health 2014; 8: 4

24 Raissi GR, Mokhtari A, Mansouri K. Reports from spinal cord injury patients: eight months after the 2003 earthquake in Bam, Iran. Am J Phys Med Rehabil 2007; 86: 912-917.

25 Blanes L, Lourenço L, Carmagnani MI, Ferreira LM. Clinical and socio-demographic characteristics of persons with traumatic paraplegia living in São Paulo, Brazil. Arq Neuropsiquiatr 2009; 67: 388-390. 
26 Levy LF, Makarawo S, Madzivire D, Bhebhe E, Verbeek N, Parry O. Problems, struggles and some success with spinal cord injury in Zimbabwe. Spinal Cord 1998; 36: 213-218.

$27 \mathrm{Hu} \mathrm{X}$, Zhang X, Gosney JE, Reinhardt JD, Chen S, Jin $\mathrm{H}$ et al. Analysis of functional status, quality of life and community integration in earthquake survivors with spinal cord injury at hospital discharge and one-year follow-up in the community. J Rehabil Med 2012; 44: 200-205.

28 Scovil CY, Ranabhat MK, Craighead IB, Wee J. Follow-up study of spinal cord injured patients after discharge from inpatient rehabilitation in Nepal in 2007. Spinal Cord 2012; 50: 232-237.

29 Singh R, Rohilla RK, Siwach R, Singh DS, Kumar MN, Singh SS. Health-related problems and effect of specific interventions in spinal cord injury. An outcome study in Northern India. Eur J Phys Rehabil Med 2010; 46: 47-53.

30 Deconinck $\mathrm{H}$. The health condition of spinal cord injuries in two Afghan towns. Spinal Cord 2003; 41: 303-309.

31 Eslami V, Saadat S, Habibi AR, Vaccaro AR, Ghodsi SM, Rahimi-Movaghar V. Factors associated with the development of pressure ulcers after spinal cord injury. Spinal Cord 2012; 50: 899-903.

32 Wannapakhe J, Arrayawichanon P, Saengsuwan J, Amatachaya S. Medical complications and falls in patients with spinal cord injury during the immediate phase after completing a rehabilitation program. J Spinal Cord Med 2013.

33 Javadi M, Hafezi-Nejad N, Vaccaro AR, Rahimi-Movaghar V. Medical complications and patient outcomes in Iranian veterans with spinal cord injury. Adv Clin Exp Med 2014; 23: 269-275.

34 Gosselin RA, Coppotelli C. A follow-up study of patients with spinal cord injury in Sierra Leone. Int Orthop 2005; 29: 330-332.

35 Chen Y, Devivo MJ, Jackson AB. Pressure ulcer prevalence in people with spinal cord injury: age-period-duration effects. Arch Phys Med Rehabil 2005; 86: 1208-1213.

36 Saunders LL, Krause JS, Acuna J. Association of race, socioeconomic status, and health care access with pressure ulcers after spinal cord injury. Arch Phys Med Rehabil 2012; 93: 972-977.

37 Leive A, Xu K. Coping with out-of-pocket health payments: empirical evidence from 15 African countries. Bull World Health Organ 2008; 86: 849-856.

38 Mares I, Carnes M. Social policy in developing countries. Ann Rev Polit Sci 2009; 12 93-113.

39 Saunders LL, Krause JS. Personality and behavioral predictors of pressure ulcer history. Top Spinal Cord Inj Rehabil 2010; 16: 61-71.

40 Gélis A, Dupeyron A, Legros P, Benaïm C, Pelissier J, Fattal C. Pressure ulcer risk factors in persons with spinal cord injury part 2: the chronic stage. Spinal Cord. 2009; 47: 651-661.

41 Rathore FA, Mansoor SN, Bin Qureshi S. Re: Burns AS, O'Connell C. The challenge of spinal cord injury care in the developing world. J Spinal Cord Med. 2012; 35: 3-8. J Spinal Cord Med 2012; 35: 194-195. author reply 5-6.

42 Rathore FA, New PW, Iftikhar A. A report on disability and rehabilitation medicine in Pakistan: past, present, and future directions. Arch Phys Med Rehabil 2011; 92 161-166.

43 Rathore FA, Mansoor SN. Factors associated with the development of pressure ulcers after spinal cord injury. Spinal Cord 2013; 51: 84.

44 Shore S, Juillerat S. The impact of a low cost wheelchair on the quality of life of the disabled in the developing world. Med Sci Monit 2012; 18: CR533-CR542.

45 Uzun 0, Tan M. A prospective, descriptive pressure ulcer risk factor and prevalence study at a university hospital in Turkey. Ostomy Wound Manage 2007; 53: 44-56.

46 Bank TW. Malnutrition prevalence, weight for age (\% of children under 5). Available from: http://data.worldbank.org/indicator/SH.STA.MALN.ZS (cited 27 January 2013).

47 Stechmiller JK. Understanding the role of nutrition and wound healing. Nutr Clin Pract 2010; 25: 61-68.

48 Mawson AR, Biundo JJ, Neville P, Linares HA, Winchester Y, Lopez A. Risk factors for early occurring pressure ulcers following spinal cord injury. Am J Phys Med Rehabil 1988; 67: 123-127.

49 Ahidjo KA, Olayinka SA, Ayokunle O, Mustapha AF, Sulaiman GA, Gbolahan AT. Prehospital transport of patients with spinal cord injury in Nigeria. J Spinal Cord Med 2011; 34: 308-311.
50 Leal-Filho MB, Borges G, Almeida BR, AeA A, Vieira MA, KaS D et al. Spinal cord injury: epidemiological study of 386 cases with emphasis on those patients admitted more than four hours after the trauma. Arq Neuropsiquiatr 2008; 66: 365-368.

51 Middleton PM, Davies SR, Anand S, Reinten-Reynolds T, Marial O, Middleton JW. The pre-hospital epidemiology and management of spinal cord injuries in New South Wales: 2004-2008. Injury 2012; 43: 480-485.

52 Edlich RF, Mason SS, Vissers RJ, Gubler KD, Thacker JG, Pharr P et al. Revolutionary advances in enhancing patient comfort on patients transported on a backboard. Am J Emerg Med 2011; 29: 181-186.

53 Bluestein D, Javaheri A. Pressure ulcers: prevention, evaluation, and management. Am Fam Physician 2008; 78: 1186-1194.

54 Michael M, Roth K. Against all odds: a qualitative study of rehabilitation of persons with spinal cord injury in Afghanistan. Spinal Cord 2012; 50: 864-868.

55 Tchvaloon E, Front L, Gelernter I, Ronen J, Bluvshtein V, Catz A. Survival, neurological recovery and morbidity after spinal cord injuries following road accidents in Israel. Spinal Cord 2008; 46: 145-149.

56 Byrne DW, Salzberg CA. Major risk factors for pressure ulcers in the spinal cord disabled: a literature review. Spinal Cord 1996; 34: 255-263.

57 Landi F, Onder G, Russo A, Bernabei R. Pressure ulcer and mortality in frail elderly people living in community. Arch Gerontol Geriatr 2007; 44: 217-223.

58 Moore ZE, Cowman S. Repositioning for treating pressure ulcers. Cochrane Database Syst Rev 2012, 9: CD006898.

59 Sweet SN, Martin Ginis KA, Latimer-Cheung AE. Examining physical activity trajectories for people with spinal cord injury. Health Psychol 2012; 31: 728-732.

60 Chan BC, Nanwa N, Mittmann N, Bryant D, Coyte PC, Houghton PE. The average cost of pressure ulcer management in a community dwelling spinal cord injury population. Int Wound J 2013; 10: 431-440.

61 Ontario HQ. Pressure ulcer prevention: an evidence-based analysis. Ont Health Technol Assess Ser 2009; 9: 1-104.

62 Ontario HQ. Management of chronic pressure ulcers: an evidence-based analysis. Ont Health Technol Assess Ser 2009; 9: 1-203.

63 Guttmann L. The problem of treatment of pressure sores in spinal paraplegics. Br J Plast Surg 1955; 8: 196-213.

64 Iwegbu CG. Traumatic paraplegia in Zaria, Nigeria: the case for a centre for injuries of the spine. Paraplegia 1983; 21: 81-85.

65 Yazicioğlu K, Gündüz S, Ozgül A, Alaca R, Arpacioğlu O. Nursing care in spinal cord injuries in Turkey. Spinal Cord 2001; 39: 47-50.

66 Nwankwo OE, Katchy AU. Outcome of a 12-week programme for management of the spinal cord injured with participation of patient's relations at Hilltop Orthopaedic Hospital, Enugu, Nigeria. Spinal Cord 2003; 41: 129-133.

67 Lederer W. Management of a tetraplegic patient in a small rural hospital in Uganda. Acad Emerg Med 1999; 6: 660-661.

68 Nwadinigwe CU, Anyaehie UE, Onyegbule EC. The impact of water mattresses on incidence of PUs in patients with spinal cord injuries in Nigeria. J Wound Care 2012; 21: 186-189.

69 Ooi AL, Julia PE. The use of unconventional pressure redistributing cushion in spinal cord injured individuals. Spinal Cord 2011; 49: 1203-1205.

70 Guimaraes E, Mann WC. Evaluation of pressure and durability of a low-cost wheelchair cushion designed for developing countries. Int J Rehabil Res 2003; 26 : 141-143.

71 Parent S, Barchi S, LeBreton M, Casha S, Fehlings MG. The impact of specialized centers of care for spinal cord injury on length of stay, complications, and mortality: a systematic review of the literature. J Neurotrauma 2011; 28: 1363-1370.

72 Reinhardt JD, Mansmann U, Fellinghauer BA, Strobl R, Grill E, von Elm E et al. Functioning and disability in people living with spinal cord injury in high- and lowresourced countries: a comparative analysis of 14 countries. Int J Public Health 2011; 56: 341-352.

73 Karlsson AK, Krassioukov A, Alexander MS, Donovan W, Biering-Sørensen F. International spinal cord injury skin and thermoregulation function basic data set. Spinal Cord 2012; 50: 512-516. 